\title{
Three-dimentional finite element analysis of a mandibular premolar with reduced periodontal support under a non-axial load
}

\author{
Sun-Mi Yang ${ }^{1}$ and Hyun-Ju Chung ${ }^{1,2 *}$ \\ ${ }^{1}$ Dental Science Research Institute, Chonnam National University, Gwangju, Republic of Korea \\ ${ }^{2}$ Department of Periodontology, School of Dentistry, Chonnam National University, Gwangju, Republic of Korea
}

\begin{abstract}
This study analyzed stress profiles of a mandibular premolar and its supporting periodontium under non-axial occlusal load as a function of the level of periodontal bone support using finite element analysis (FEA) and compared biomechanical behaviors to the profile under axial loading. A composite three-dimensional FEA model of a lower second premolar and its supporting tissue was developed using scanned image and computed tomography (CT) data. Material properties for enamel, dentin, periodontal ligament (PDL), and alveolar bone were used in this analysis. Four levels of periodontal support were simulated by varying the bone level, and a $90 \mathrm{~N}$ load was applied axially on the buccal cusp or $45^{\circ}$ non-axially on inner inclines to simulate vertical or lateral forces. Finally, the von Mises stress (VMS) was calculated using FEA software. The non-axial load resulted in a peak VMS at the cervical enamel region, regardless of the bone level, and in extensive concentration of the peak VMS at the root dentin, PDL, and bone crest opposite to the loading direction, which increased with decreased periodontal bone support. The stress concentration along the root and PDL to the non-axial load shifted apically with periodontal bone support decrease. In the PDL and alveolar bone, the increase in peak VMS was significant with less than half of the bone height. Non-axial occlusal loads present asymmetric stress distribution in root dentin and PDL at the crest level, depending on the loading direction, with a significant increase in severe bone reduction $(\geq 50 \%)$. The periodontal bone support decrease shifts the peak stress apically away and can result in apical extension of the root defect.
\end{abstract}

Key Words: Lower premolar, Non-axial load, Reduced bone support, Secondary occlusal trauma

(c) This is an open-access article distributed under the terms of the Creative Commons Attribution Non-Commercial License (http://creativecommons.org/licenses/by-nc/4.0) which permits unrestricted noncommercial use, distribution, and reproduction in any medium, provided the original work is properly cited.

\section{INTRODUCTION}

Premolars are frequently involved in occlusal trauma showing mobility because of the smaller size of the teeth [1,2], the specific morphology and occlusion of these teeth in their position within the arch. These premolars are also the teeth with most non-carious cervical lesions (NCCLs) in prevalence and severity [3-6] and these increased with age
[4,5]. The higher presence of NCCLs in premolars could be explained by the higher incidence of occlusal loading [4,7] and the higher number of premature contacts found in these teeth [8]. Premolar teeth are positioned in the dental arch where the lateral loading occurs frequently rather than axial physiological loading during functional and nonfunctional occlusion. In clinic, cervical defects are frequently observed in premolars of aged individuals who have ex-

Received November 11, 2019; Accepted November 26, 2019

*Corresponding author: Hyun-Ju Chung, Department of Periodontology, School of Dentistry, Chonnam National University, 33 Yongbong-ro, Buk-gu, Gwangju 61186, Republic of Korea.

Tel: +82-62-530-5822, Fax: +82-62-530-0130, E-mail: hjchung@jnu.ac.kr

Copyright $\odot$ 2019, Oral Biology Research Institute 
perienced periodontal bone loss. According to the 10-year longitudinal epidemiologic study for intra-oral pattern of tooth and periodontal bone loss between the age of 50 and 60 years $[9,10]$, upper 2 nd premolars and upper and lower molars had a higher mortality rate $(7.5 \%$ of the aged $>50$ years). The lower premolars having bone loss of $2 \mathrm{~mm}-5$ $\mathrm{mm}$ (equivalent to $1 / 4-1 / 2$ bone loss) were still in function with or without molar occlusion.

Generally, the extent of tissue changes from occlusal trauma in dentine and periodontal tissues could be directly related to the magnitude and direction of the forces applied to tooth. As for loading direction, a role of occlusal forces was demonstrated in upper [11] and lower premolars $[12,13]$. The occlusal force leaning against the tooth axis under the asymmetrical loading causes the tooth to bend, and higher tensile stresses occurs on the cervical region at the side opposite of the loading point, which leads to plastic deformation of the enamel surface. As the tensile yielding strength of enamel is much smaller than the compressive and the shear ones, the enamel surface in the tensile state tends to suffer plastic deformation. They reported that the type of occlusal loading has the biggest influence on cervical stress intensity and exposure to stress would lead to its progression. On the clinical aspect, further attention should be paid to the importance of the occlusal adjustment for the treatment of cervical tooth defects, if oblique force loading on teeth contributes the major cause of the cervical lesion.

As for the supporting bone levels, the gingival recession and periodontal bone loss increases with aging and the bending phenomenon of crown portion increases and finally results in different and extensive stress distribution in tooth and its periodontal tissue, compared to the tooth with normal bone height. In addition, the action of occlusal forces, especially paraxial loading or lateral premature contact could lead to increased stress concentration on the tooth and supporting tissue. However, only a few studies reported the stress distribution in tooth with reduced periodontal support for periodontal ligament (PDL) stresses following functional or nonfunctional occlusal loading on upper central incisor $[14,15]$ or for the cervical lesions in upper premolar [16-18]. In the latter recent finite element (FE) study with existing cervical lesions, non-functional loadings exhibited tensile stresses concentrating at the cervical areas and root surfaces with a trend of stress amplification was observed with decreasing bone height [18]. With the rise of elderly population with retaining teeth, the cumulative increase of the alveolar bone loss due to periodontal disease and the resulting increased clinical crown length might be associated with increased prevalence of occlusal trauma and cervical defect in this population. However, the biomechanical analysis has been very rare in mandibular premolars with reduced periodontal tissue under non axial loading.

This study aimed to investigate the stress profile of tooth and its supporting tissue, especially in the cervical region and root area of a lower 2 nd premolar with reduced bone support under different type of occlusal loading (axial and non-axial).

\section{MATERIALS AND METHODS}

\section{The three-dimensional solid model generation}

The tooth was selected based on its lack of carious lesions, and absence of abnormalities, which could simplify interpretation of results of a sound tooth model for FE analysis. To develop a three-dimensional (3D)-FE model based upon actual geometric dimensions, sequential software processing was performed. The extracted left mandibular 2nd premolar tooth was scanned using 3D scanner (Freedom HD; DOF Inc., Seoul, Korea). Obtained surface contours and meshes were then imported into SolidWorks 2015 software (Dassault Systemes SolidWorks Corp., Waltham, MA, USA), and 3D solid model of the intact lower 2nd premolar (with total tooth length of $19.8 \mathrm{~mm}$, crown height of $6.7 \mathrm{~mm}$, and root length of $13.1 \mathrm{~mm}$ ) was generated by using a "SCANto3D" add-in module.

Interfacial surface between dentin and enamel were made by lofting technique of the computer-aided design program according to the anatomy of natural tooth (eHuman 3D Tooth Atlas 7.6; eHuman Inc., Fremont, CA, USA). Once enamel and dentin 3D volumes were generated, Boolean operations were used to ensure congruence between the related interfacial surfaces. The enamel volume was created by subtracting the dentin volume. Then, the 
enamel and dentin 3D volume was combined to make a final 3D solid model of the intact mandibular second premolar. Additionally, based on the outer geometry of the model, PDL and alveolar bone (cortical and spongious) were created. The PDL, cortical bone, and spongy bone were modeled around the tooth root. Thicknesses of the PDL, lamina dura, and outer cortical bone were assumed to be $0.25 \mathrm{~mm}, 0.4 \mathrm{~mm}$, and $1.1 \mathrm{~mm}$ respectively, according to the average anatomical dimensions obtained from the CT data of patients treated at Chonnam National University Dental Hospital in Gwangju, Korea (Fig. 1). The cementum layer was not considered in this model due to small thickness and the properties similar to dentin [19] and the pulp was also disregarded.

Bone levels were varied to represent different stages of periodontal tissue destruction. The alveolar bone crest was placed $0.8 \mathrm{~mm}-9.1 \mathrm{~mm}$ apical from the cemento-enamel junction (CEJ) in models $1,2,3$, and 4, respectively to simulate the tooth with normal periodontal support, $1 / 3$ bone loss, 1/2 bone loss, and 2/3 bone loss (Fig. 2).

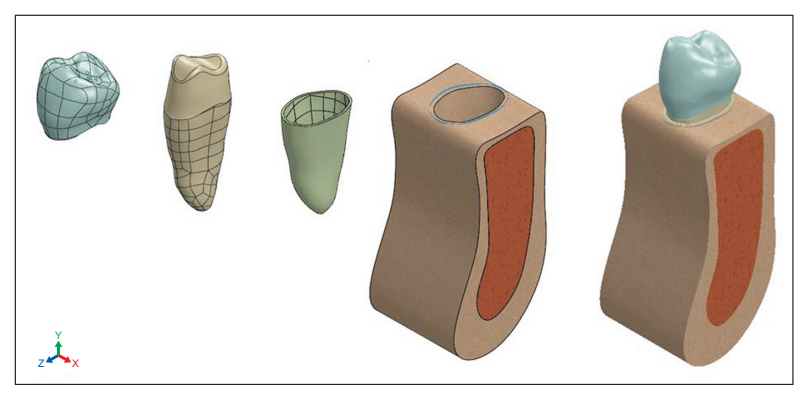

Fig. 1. Three-dimensional volumetric models for dental tissues and supporting structures reconstructed from scanned images and computed tomography images; surfaces of the structures: enamel, dentin, and periodontal ligament and supporting bone, and finally assembled model.

\section{Finite element analysis}

Four 3D solid models were meshed with tetrahedral elements. The number of elements and nodes varied according to the model $(35,822-58,475$ elements and 52,352-83,802 nodes). All models were assumed to be fixed at the mesiodistal cross-section of alveolar bone, with no rotation or translation allowed in any direction. The mandibular bone sectional edges which restricted the displacement along the $\mathrm{Z}$ axis. All nodes on the lower surface of the cortical bone were constrained in all directions (X, Y and $\mathrm{Z}$ ), preventing rigid body displacement, as the boundary conditions for all models. The materials from the different structures in the models were assumed to have homogenous, isotropic, linear elastic properties, represented by the Young's modulus of elasticity and the Poisson's ratio (Table 1) [15,20-23].

To simulate functional occlusal forces in vertical direction, the static axial load (V) with the total load of $90 \mathrm{~N}$ was applied on the tooth at 3 occlusal contact points (buccal cusp tip and its mesial and distal slopes). To simulate lateral forces or nonfunctional paraxial loads on the slope of occlusal surface, the total force of $90 \mathrm{~N}$ was applied at $45^{\circ}$ buccal or lingual to the long axis on the occlusal slope contact point of a tooth (lingual incline of the buccal functional

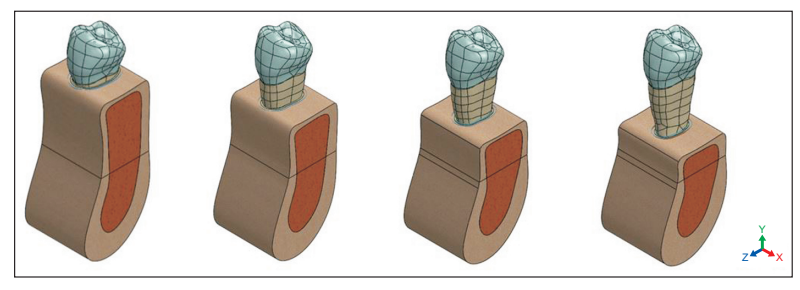

Fig. 2. Four three-dimensional models in which the bone levels were varied to represent different stages of reduced periodontal support $(0$, $1 / 3,1 / 2$, and $2 / 3$ lost). The alveolar bone crest was placed $0.8,4.8,7.0$, and $9.1 \mathrm{~mm}$ apical to the cemento-enamel junction of the tooth in models $1,2,3$, and 4 , respectively.

Table 1. Material properties

\begin{tabular}{lccc}
\hline Anatomic structure & Young's elastic modulus (MPa) & Poisson's ratio & Reference \\
\hline Enamel & 84,100 & 0.30 & Magne 2007 [20] \\
Dentin & 18,600 & 0.32 & Zarone et al. 2006 [21] \\
Periodontal ligament & 68.9 & 0.45 & Reinhardt et al. 1984 [15] \\
Cortical bone & 10,000 & 0.30 & Farah et al. 1989 [22] \\
Spongious bone & 1,370 & 0.31 & Geng et al. 2001 [23] \\
\hline
\end{tabular}


cusp (simulating balancing contact on inner incline of buccal cusp, BB); or buccal incline of the lingual nonfunctional cusp (simulating working contact on inner incline of lingual cusp under non-axial loads, WL), which represented working or balancing nonfunctional contacts (Fig .3) [24,25].

The contact interfaces between teeth, PDL and bone were treated as tie-constraint that was used to determine one surface tied to another without sliding, in order to simulate the attachment of the teeth to alveolar bone through PDL. The processing stage or solution analysis was performed with SolidWorks 2015 software, and this software also used in the post processing for the visualization and evaluation of the analyzed results. The von Mises stress (VMS) values were calculated as the stress criteria to present the stress distribution in the models in the enamel, dentin, PDL, cortical, and cancellous bone.

\section{RESULTS}

\section{The pattern of stress distribution in composite models}

The VMS profiles in composite 3D finite element analysis (FEA) model are shown in Fig. 4. Under axial loading, there was only slight variation in the stress distribution and intensity in tooth and supporting structures according to the supporting bone levels, whereas extensive variation in stress intensity and distribution was seen in root and periodontal structure under non-axial loading conditions. The highest VMS stresses were found inside the occlusal enamel at the load application area of crown. The enamel and dentin in the cervical area are the next parts bearing the highest stress.

In the sagittal section image, the peak stress distributed along the dentino-enamel junction in the model 1 with normal bone level, and this stress distribution shifted apically along the root surface near to bone crest in model 2 , 3, and 4 with variable amount of bone loss (Fig. 4B). Under axial loading, similar pattern of stress distribution was observed on the root dentin adjacent to socket bone in models 1,2 , and, 3 , respectively. In the model 4 with only $1 / 3$ bone support, there was greater and extensive stress distribution along the buccal root surface at the apical 1/3.

Non-axial loading at $45^{\circ}$ angle create a bending moment causing fiexure of the tooth resulting in peak VMS on the buccal or lingual surface of the root dentine depending on the direction, adjacent to the bone crest at which the fulcrum was located (Fig. 4B). Different to normal bone support, the non-axial loadings resulted in prominently increased peak VMS on the surface of the radicular dentine, near to bone crest in bone reduction models 2 and 3. In model 4 with apical 1/3 bone support, intense and exten-

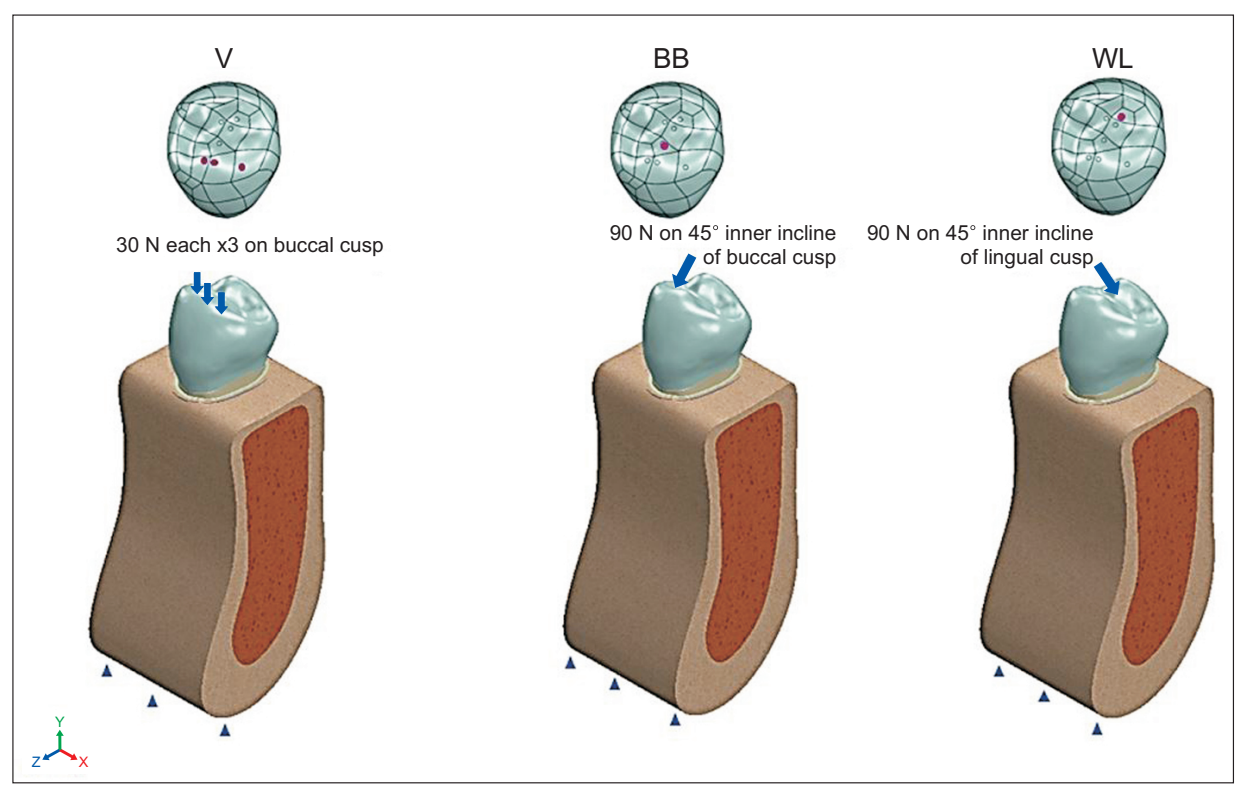

Fig. 3. Type of simulated occlusal contacts were in centric occlusion (as vertical axial load, V), balancing laterotrusion (as balancing non-axial lingual load, BB), and working laterotrusion (as working non-axial lingual load, WL), and boundary conditions and fixation of the models. Lower surface of the cortical bone were constrained in all directions. $\mathrm{V}$, under axial load; BB, simulating balancing contact on inner incline of buccal cusp; WL, simulating working contact on inner incline of lingual cusp under non-axial loads. 
A

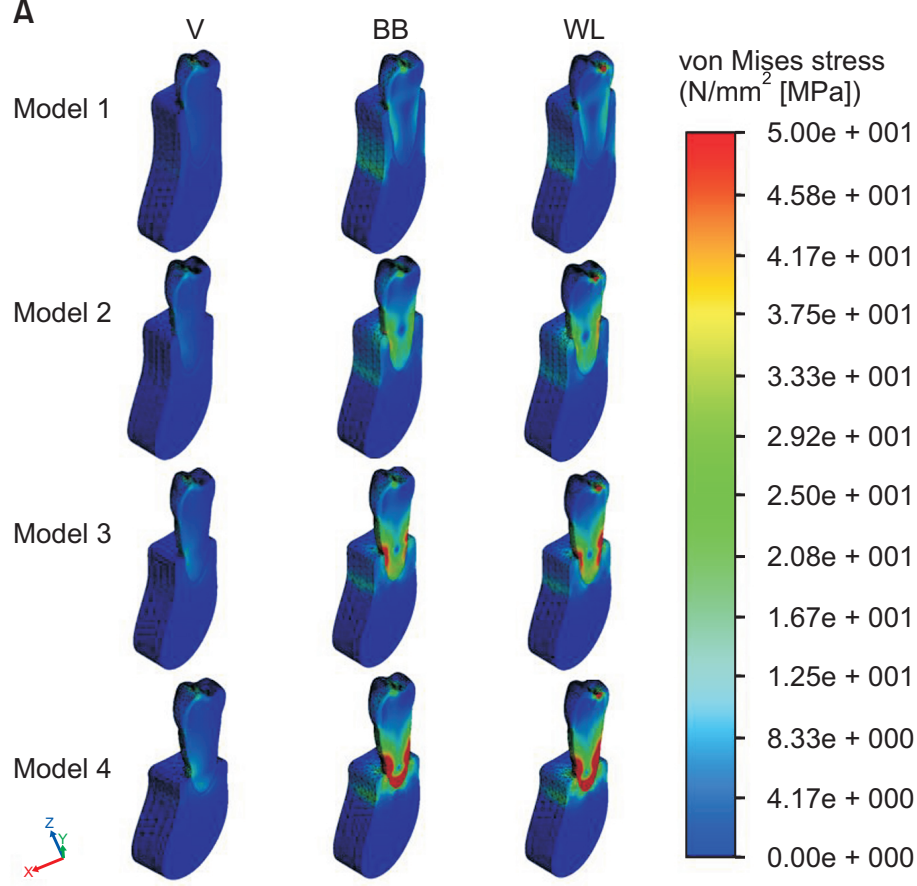

B

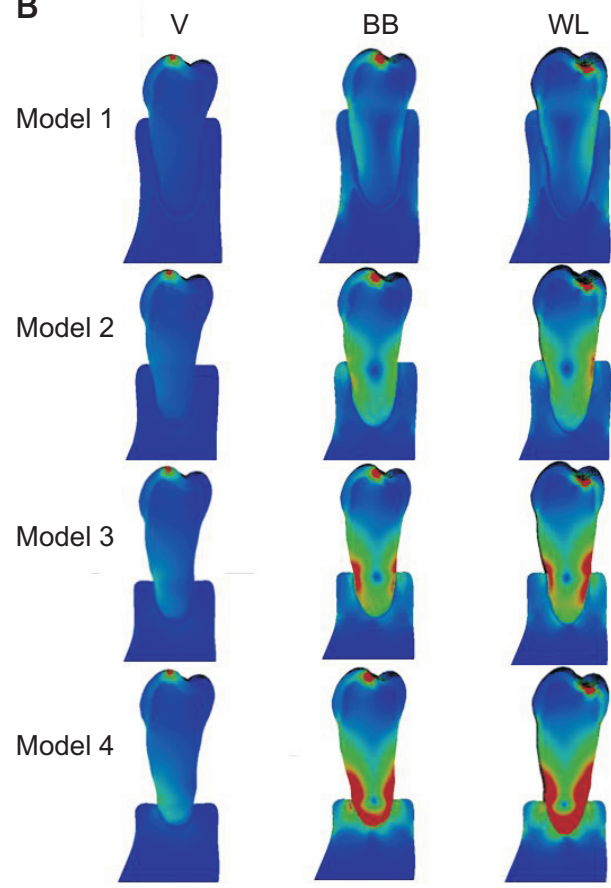

Fig. 4. von Mises stress profile in 4 composite three-dimensional finite element analysis models of lower 2nd premolars (A) and in the buccolingual sagittal image (B) under axial (V) and 2 non-axial (BB, WL) loading conditions. Under 2 non-axial loadings (BB and WL), the center of rotation apically shifted with the decreasing bone crest level. V, under axial load; BB, simulating balancing contact on inner incline of buccal cusp; WL, simulating working contact on inner incline of lingual cusp under non-axial loads.

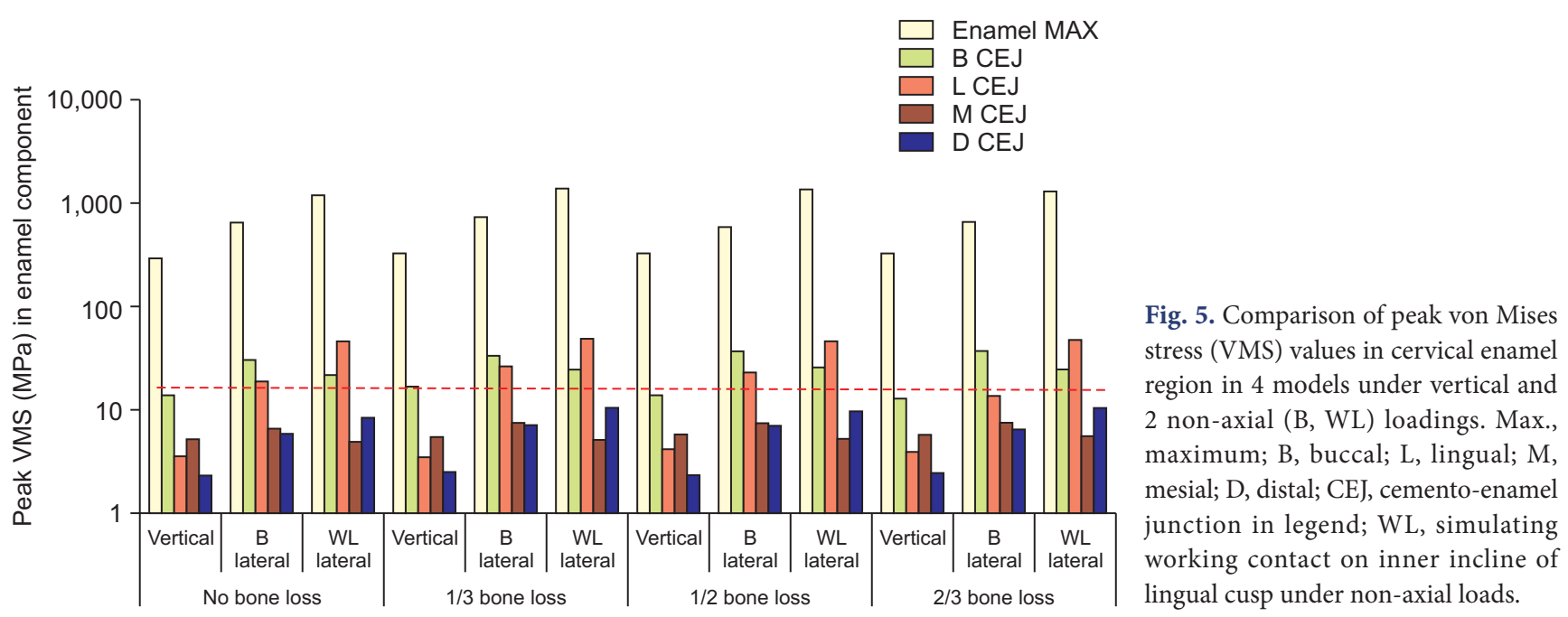

sive stress distribution was observed approaching to the root apex.

\section{The stress profile in tooth crown component}

Stress distribution profile in CEJ region was similar, re- gardless of the supporting bone levels, whereas there was prominent increase in the stress intensity to non-axial loadings (Fig. 4B, 5). Stresses on cervical region under axial loading were highest at the buccal surface (14-17.1 MPa) and minimal at lingual and proximal surfaces with the range of 2-6 MPa. The peak lingual VMS was approximate- 
ly $1 / 4$ of buccal cervical peak values.

Vertical and BB loadings resulted in greater stress concentration in buccal CEJ than the lingual, and WL loading resulted in greater VMS concentration in lingual CEJ than the buccal. The influence of supporting bone level was minimal and the buccal stress increased by 15\% in model 3 and 4 , under BB and WL loadings both.

\section{The stress profile in dentinal root}

Under axial loading, peak VMS of $10 \mathrm{MPa}$ was shown along the buccal root surface, especially concentrated on the crest area, in model 1. Similar profile of stress distribution was observed in root dentin near to bone crest under axial loading in bone reduction models 2 and 3, showing VMS profile separated between superior and inferior to the bone crest level, and extensive stress concentration distributed on the buccal- apical region in the model 4 with $1 / 3$ bone support.

Under non-axial loading, the peak VMS increased in all models, compared to axial loading. The highest peak VMS in models 1 and 2 was observed on the lingual cusp incline of load application under WL load and the relatively lower peak VMS at buccal or lingual cervical area under the axial and BB loads. However, models 3 and 4 with more than $1 / 2$ bone loss showed increased peak stress along the root surface near to bone crest, at buccal or lingual depending on the loading and the supporting bone levels. In model 4 , intense VMS (5-7 times to model 1 value) concentrated and extended to the apex (Fig. 6). Stresses on root surface at the bone crest was increased at the lingual surface on WL loading in model 2 and 4, whereas BB loading resulted in greater stress at the buccal surface in model 3 .

In root apex, peak dentinal VMS values was only $1-2 \mathrm{MPa}$ in model 1 under axial load, and increased over $50 \mathrm{MPa}$ in model 4, under non-axial loadings. With bone reduction, the peak VMS magnitude increased on crestal root surface as well as on apical region, showing more dramatic rise of peak stress in root apex than near to bone crest.

\section{The stress profile in periodontal ligament}

VMS profile showed the peak VMS value in internal portion of PDL at the opposing side to the direction of nonaxial loadings in which the stress value increased to 5-6 times, compared to axial loading (Fig. 7A, 8).

The peak VMS in PDL component at buccal and lingual bone crest under axial loading was $0.08,7.06,11.7$, and $14.8 \mathrm{MPa}$ in 4 models respectively, and increased with increasing bone loss. Under all loadings, peak VMS stress levels increased in PDL, both at bone crest and at root apex both with bone reduction with much lower peak VMS in apical than crestal PDL. Under non-axial loadings, maximum VMS increased approximately 4-9 times in the internal portion of crestal PDL in 4 models respectively, near to buccal bone crest under BB load and near to lingual bone crest under WL load.

In apical PDL portion, peak VMS values was 1.2-2 MPa in models 1 and 2, and 3.2-8.8 MPa in models 3 and 4, showing 3-5 times increased intensity in severe bone reduction

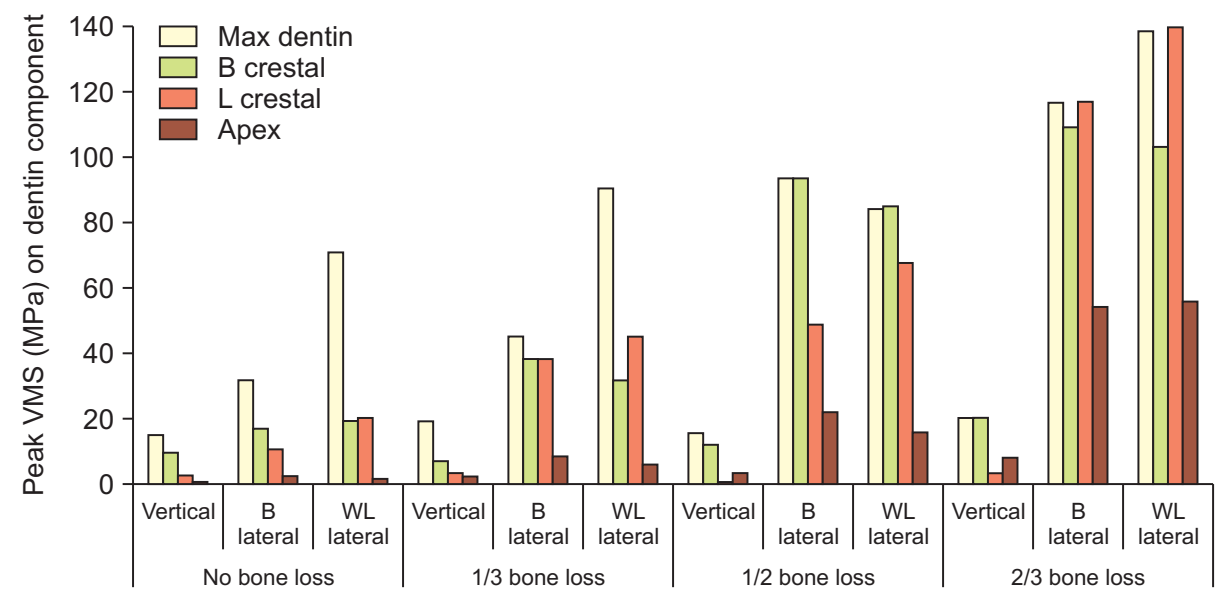

Fig. 6. Comparison of peak von Mises stress (VMS) values in root dentin region near bone crest in 4 models under vertical and 2 non-axial (B, WL) loadings. Max., maximum; B, buccal; $\mathrm{L}$, lingual in legend; WL, simulating working contact on inner incline of lingual cusp under non-axial loads. 
A

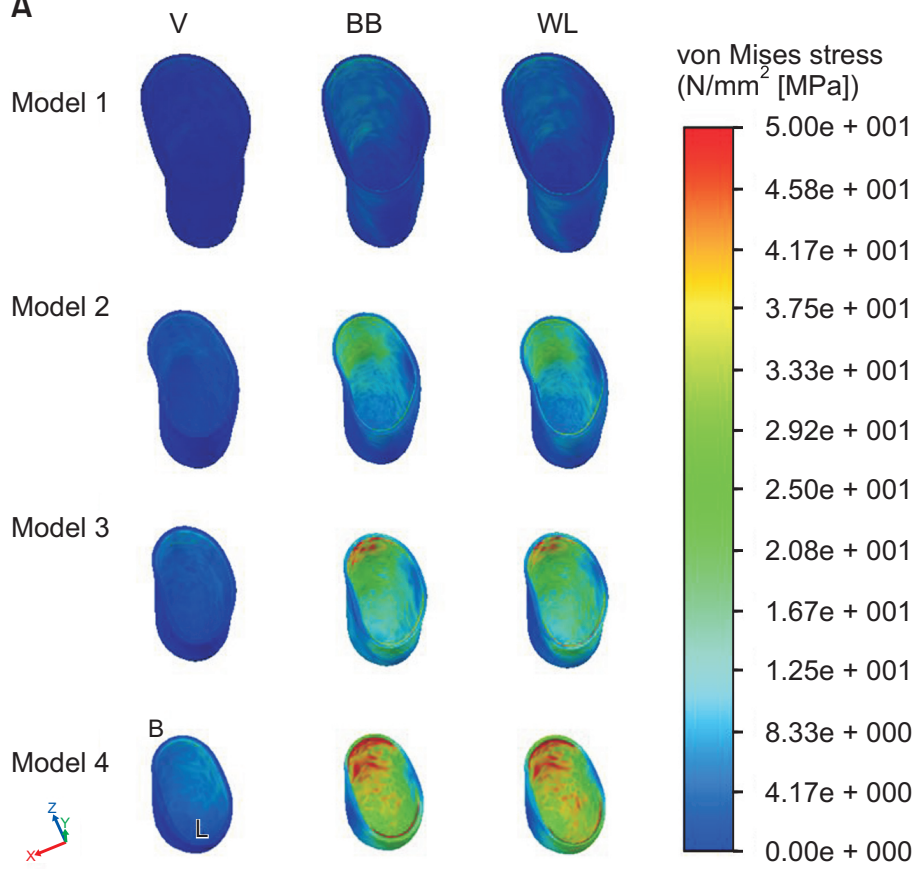

B

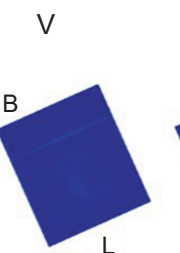

BB

WL

Model 1
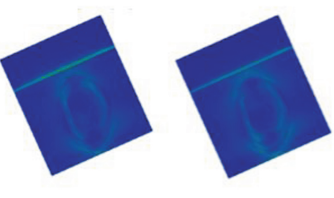

Model 2
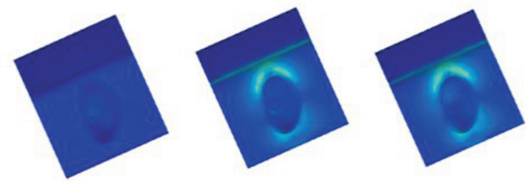

Model 3
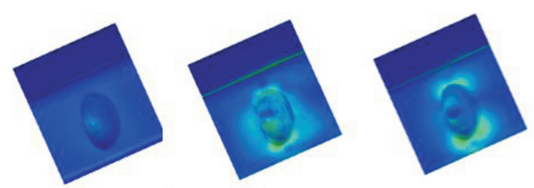

Model 4
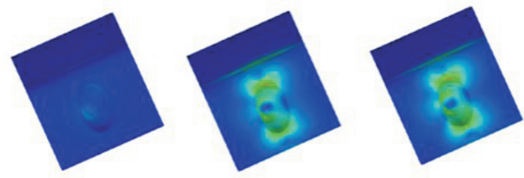

Fig. 7. von Mises stress profile in periodontal ligament (A) and alveolar bone components (B) from the frontal view in 4 models under axial (V) and 2 non-axial (BB, WL) loadings. V, under axial load; BB, simulating balancing contact on inner incline of buccal cusp; WL, simulating working contact on inner incline of lingual cusp under non-axial loads; B, buccal; L, lingual.

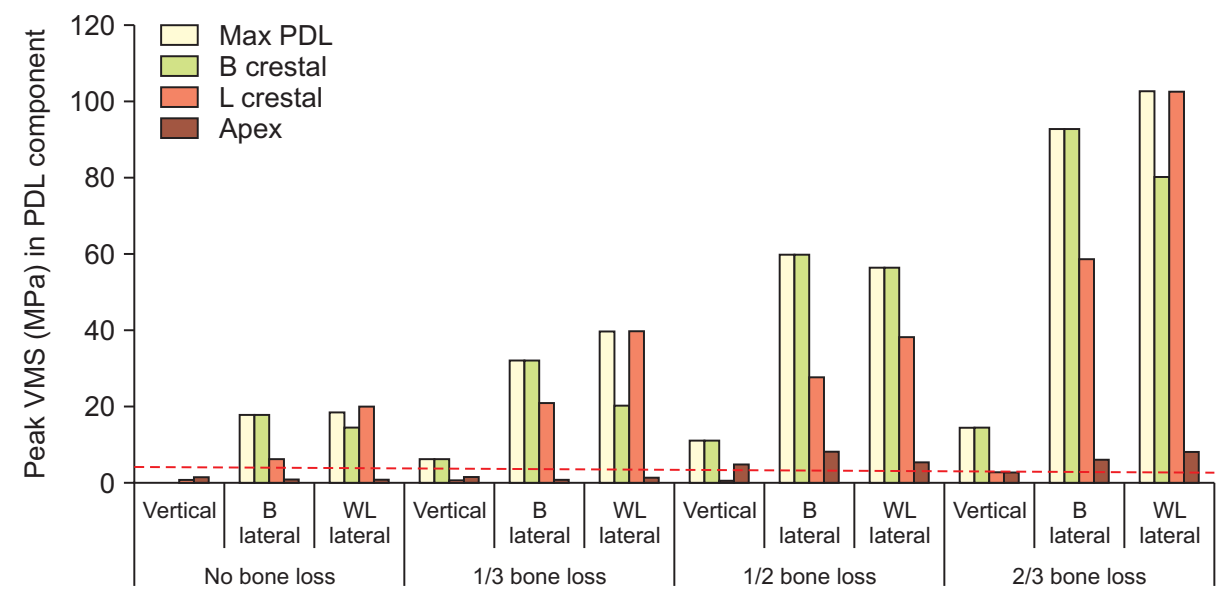

Fig. 8. Comparison of peak von Mises stress (VMS) values in periodontal ligament component according to the supporting bone levels in 4 models under vertical and 2 non-axial (B, WL) loadings. PDL, periodontal ligament; Max., maximum; B, buccal; L, lingual in legend; WL, simulating working contact on inner incline of lingual cusp under non-axial loads. models ( $\geq 50 \%$ ) (Fig. 8).

\section{The stress profile in alveolar bone component}

The profile of peak VMS distribution in bone was very similar to the profiles in PDL at both crestal and apical area (Fig. 7B). Peak VMS concentration was observed in apical bone to axial loading and in crestal bone to the non-axial loadings, much greater than the peak apical VMS under axial loading. The peak stress values in bone was ranged between $1 / 10$ and $1 / 2$ of the corresponding values on PDL component at crest, whereas around root apex the VMS values were similar between bone and PDL component.

Non-axial loading resulted in 6-10 times higher peak VMS at alveolar bone crest in all models, compared to axial loading. In the stress profile of alveolar bone crest, 


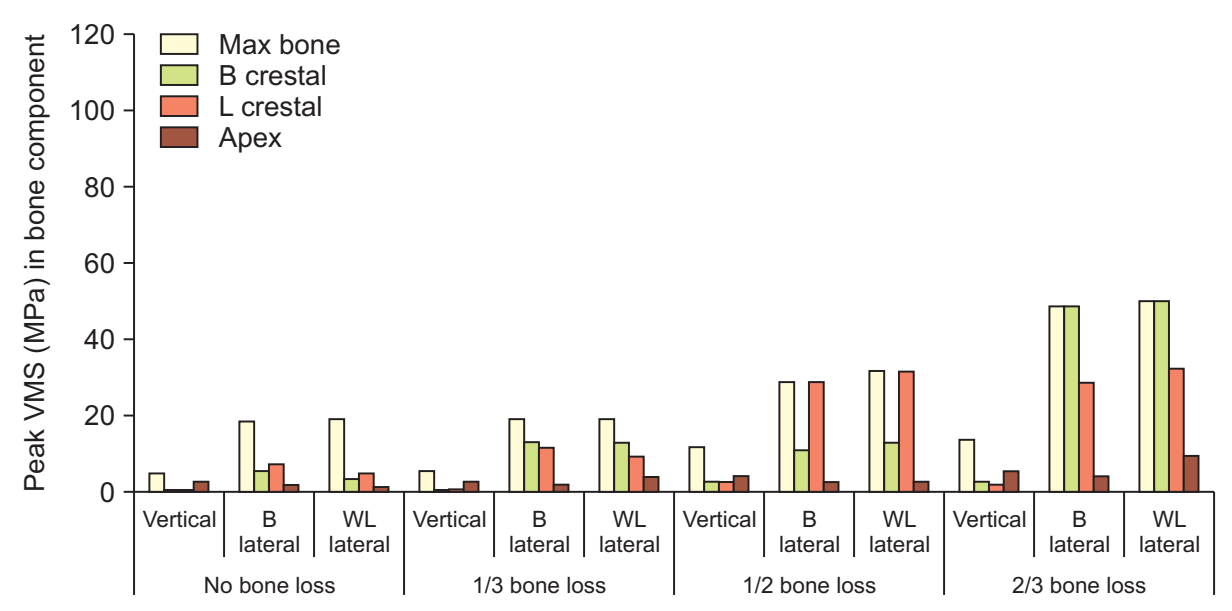

Fig. 9. Comparison of peak von Mises stress (VMS) values in bone component according to the bone levels in 4 models under vertical and 2 non-axial (B, WL) loadings. Max., maximum; B, buccal; L, lingual in legend; WL, simulating working contact on inner incline of lingual cusp under non-axial loads. peak VMS in model 3 and 4 increased to 3-5 times to axial loading and increased to 2-13 times to non-axial loadings, compared to the model 1 . In stress profile of apical bone, peak VMS in models 3 and 4 with severe bone loss increased to $1.5-2$ times under axial loading and increased to $1.2-1.5$ times and to $2-5$ times respectively under nonaxial loads, compared to model 1 (Fig. 9).

\section{DISCUSSION}

Secondary occlusal trauma occurs in a tooth with a reduced height of the periodontal attachment [26] and the force itself may not necessarily be abnormal but excessive for the weakened periodontium. As the biologic reactions of the PDL, the tooth tends to tilt in the direction of the applied tipping forces, by the orchestrated reactions of the PDL tissues by the creation of compressive and tensile stress zones within the cervical and apical parts of the attachment apparatus [27]. The forces caused by occlusal trauma could decrease perfusion of the PDL resulting in ischemia and necrosis of the PDL cells when the adaptive capacity of the PDL is exceeded [28]. Hence, the stress could affect the integrity of periodontal structures and the occlusal trauma might be a catalyst for the destructive processes initiated by bacterial inflammation [29,30]. Clinical evidences supporting the abnormal occlusal contacts and secondary occlusal trauma, as a risk factor in periodontitis progression and tooth longevity eventually were found in a series of retrospective studies by Harrel and Nunn's studies [30,31] and others [32,33].
According to the FEA result using central incisor model by Reinhardt et al. [15], the mean maximum principal PDL stress at the alveolar crest was approximately 3 times greater in model with 60 percent bone loss, suggesting that $1 / 3$ magnitude of the occlusal load could generate the stress necessary to initiate the lesion of secondary occlusal trauma with 60 percent bone loss, as compared to the lesion of primary occlusal trauma with normal bone height. Other 3D FEA further demonstrated that traumatic occlusal contact generated stress is harmful to the periodontal tissue integrity [19]. PDL as the most formative tissue has its important role in healing and regeneration of periodontium after therapy. Reducing the stresses in the PDL may provide a better condition for this tissue component to maintain its regenerative and physiologic functions without trauma.

As for NCCLs, it was shown in simulated FE model that that stresses were concentrated at the CEJ in all axial and non-axial loadings, and lateral loading produced maximum stresses greater than axial loading $[11,12,18,25]$. The oblique loading created a greater bending moment and flexure of the tooth and the resulting bending moment to the tooth depends on the direction of the force and the factors, such as the ratio between the extra- and intra-alveolar arm (representing the clinical crown length and the bone level surrounding the root) [12]. Recent systemic review [34] found the majority of studies reported an association between occlusal stress and NCCLs. There are abundant studies for mechanism of NCCLs using lower premolar model [24,35-39]. However, the profile of stress distribution in lower premolars and their periodontium as effector tissue 
of occlusal trauma was rarely reported.

Our concern was to evaluate the effect of secondary occlusal trauma in periodontal tissue as well as the cervical lesions in tooth, under non-axial loading combined with reduced bone support. Therefore, this study investigated the stress profile in tooth and its periodontium of a lower 2nd premolar under $90 \mathrm{~N}$ of axial or non-axial loading condition according to the variation of bone support.

As for the magnitude of applied force, the average maximum biting force of a second premolar was estimated as $291 \mathrm{~N}$ during bilateral clenching [40]. The intensity of simulated loading force was set to $90 \mathrm{~N}$, considering the average chewing force as 36\%-40\% [41,42] of the maximum biting force. It was shown that increased loading did not cause changes in the overall pattern of stress distribution, but amplified its intensity [11].

For the purpose of presenting the action of functional axial loading (V), occlusal contacts were simulated on regions that imitate teeth contacts at the buccal cusp tip in central occlusion on lower 2nd premolar. In addition, 2 paraxial loadings were simulated on the internal inclines of lingual and buccal cusp, at $45^{\circ}$ buccal and lingual to the long axis for working (WL) or balancing interference (BB). These loading conditions were based on the results described in Palamara et al. [38] and Rees [25]. In the latter study, BB loading and WL loading resulted in higher peak maximum principal stress at cervical enamel than on the buccal incline load for working.

In our result, peak VMS values in cervical enamel were 32 and 22.6 MPa at buccal CEJ and 19.2 and $47.9 \mathrm{MPa}$ at lingual $\mathrm{CEJ}$ under $\mathrm{BB}$ and WL loadings respectively, above the known failure stress level for enamel (10-24 MPa [43]) Our study with normal bone model under non-axial loadings showed VMS level increased 2.5 times (14.4 vs. 32.3 $\mathrm{MPa}$ ) in enamel region at the buccal cervical tooth area, compared to the axial load. For the normal bone model, some localization of stress was observed around the CEJ, whereas this stress localization became less evident and the peak VMS intensity did not increase for the periodontally reduced models.

In dentin component, peak VMS of $10 \mathrm{MPa}$ was shown along the buccal root surface, especially concentrated near to the crest, and very low values at lingual and apical dentin in normal bone height under axial load. Under non-axial loading, the peak VMS increased to $\times 2, \times 5$, and $\times 2$ value at buccal cervical, lingual cervical, and apical dentin of the stress under axial loading. The highest peak VMS was observed on the lingual cusp incline of load application under WL load (imitating working interference) and the relatively lower peak VMS at buccal or lingual cervical area under the axial and BB loads (imitating balancing interference). In root apex, peak VMS values was relatively low (1-2 MPa) in normal bone model 1, and increased twice under non-axial loadings.

Concerning the stress distribution in tooth with the reduced periodontal support, the reduction of periodontal support shifted the location of highest stress away along the root surface apically from the CEJ and was located just above the bucco-alveolar crest. The peak VMS at the CEJ was not changed substantially regardless of periodontal support and varied according to the loading condition similar to others [17]. However, the peak VMS on root area increased substantially and concentrated on the root surface at bone crest level, and the distribution was more extensive with reduced periodontal support, under both axial and non-axial loading conditions, showing variation depending on the loading condition. The influence of reduced periodontal support was prominent by $\times 2$ and $\times 3$ increase of peak dentin stress in models 3 and 4 and this area of stress concentration increased in size and magnitude and the center of peak VMS moved apically on the dentinal root periphery with bone reduction. The stress distribution on the lingual root dentin also increased in size, magnitude, and shifted apically as bone levels decreased, as previous reports in upper central incisor FE model [15] and upper premolar photoelastic models [17].

At apical root dentin, the peak VMS level related to model 1 increased dramatically to 6.9 times under axial loading, and increased to 6.7-10 times under 2 non-axial loadings in model 4 . The peak VMS at root dentin near buccal and lingual bone crest in model 3 and 4 with 50\%-67\% of bone loss increased dramatically, reaching and exceeding the tensile strength of dentin of 103-105 MPs [43] or lower strength of dentin near to pulp (35-62 MPa [44]). Especially in model 4, peak dentinal VMS on was found root dentin near to lingual bone crest, differently to 3 other models 
with peak VMS near to buccal crest. This suggests that the progression of lingual cervical lesion near bone crest is possible in severe bone reduction model (corresponding to $67 \%$ bone loss) as well as buccal cervical lesion, independent to the loading direction. If pre-existing lesions are narrow and angular at the CEJ, and some extend broadly into the root region or if the process of abfraction were to begin in dentine above the bone crest level, it could quickly spread to involve the adjacent tooth substance, producing the subgingival lesions that are sometimes seen clinically. In addition, existing cervical- root lesions are more likely to occur in teeth with compromised periodontal tissue. Different distortions in the tooth structure may also occur besides simple cantilever bending, especially in periodontally compromised or crowded teeth [39]. The abfractions are less likely to occur on a tooth with diminished periodontal support, and if does occur, must be more apically located [45]. Our study showed that with decreasing periodontal support the location of the highest stress concentration tended to shift away from CEJ which is supposed to be susceptible to abfraction at root (not CEJ), toward the apical dentin region. This situation has been frequently found clinically. The rate of gingival recession and the lack of tooth mobility could constitute predisposing factors for the progression of cervical defect because the exposed root surfaces could be more susceptible to abrasion and/or erosion, and the nonmobile teeth resisting strongly against frictional forces, thus abrasive effects, could possibly develop cervical wear [45]. Whether the firmness of the tooth in the socket creates a fulcrum, which favors stress accumulation causing abfractive effects at the tooth cervix has to be investigated. Any type of stress (tensile, compressive, or shearing), in sufficient magnitude, can inflict damage on the tooth structure. Tooth flexure has been described as a lateral or axial bending under occlusal loading, tooth flexure produces tensile or compressive strains in cervical region, causing a disruption of the bonds between hydroxyapatite crystals leading to crack formation in the enamel, and the eventual loss of enamel and underlying dentin [46].

The peak VMS in PDL to the root in normal bone model could be calculated to be $2 / 3-1 / 2$ of the stress, which is likely due to the much lower value of Young's modulus for the PDL than for dentin or bone [15]. In PDL component, the peak VMS was 0.08 and $18.7 \mathrm{MPa}$ in buccal crestal PDL, 0.97 and $19.6 \mathrm{MPa}$ in lingual crestal PDL and 1.73 and 1.29 MPa in apical PDL in model 1 under axial and non-axial loading, respectively. This suggests that PDL could be damaged under non-axial loadings in normal bone with produced stress exceeding the reported tensile strength of PDL (2.4 MPa; [47]). With gradual bone loss, peak VMS under axial loading increased to $\times 88-185$ at buccal crest in bone reduction models and increased 3 times at lingual crest in model 4 only, compared to model 1 . Under non-axial loadings, peak VMS increased to $\times 3.3, \times 5$ at buccal crest and to $\times 4.5, \times 9$ at lingual crest in modes 3 and 4 respectively. In apical PDL, the peak VMS increased 3 times and 2 times in models 3 and 4 under axial loading respectively, and increased to 5-7 times in models 3 and 4 both under non-axial loadings. Compared to the PDL stress under axial loading, the intensity rise under non-axial loadings increased approximately to $\times 5, \times 35$, and $\times 2$ at PDL near to buccal and lingual crest, and at apex respectively, in all bone reduction models. Especially the model 3 showed peak VMS concentration was always shown at buccal crest under axial and non-axial loads, differently to models 2 and 4 showing the peak VMS on lingual crestal PDL under WL loading. Under non-axial loadings the PDL stress values at buccal and lingual bone crest exceeded the PDL tensile strength in all bone reduction models. PDL stress near to buccal crest increased with bone reduction and exceeded the PDL strength under axial loading, whereas the values at apex were lower in models normal bone and $1 / 3$ bone loss. This finding indicates that PDL undergoes damage at buccal and lingual crest under non-axial loading in all models regardless of bone height, and could be traumatized at buccal crest in models with bone reduction even under axial loading. In addition, apical PDL could dissipate the stress very well with the normal bone model 1 and model 2 , although this stress values in models 3 and 4 with $1 / 2$ and $3 / 2$ bone loss was still higher than tensile strength of PDL of $2.4 \mathrm{MPa}$ [47] or 6.82 MPa [48]. This finding also seems to be related with the apical shifting of rotation center as seen the similar pattern in dentin stress distribution. Similarly to our result, a recent FEA demonstrated that with the weakened periodontal support or more appropriately secondary occlusal trauma, the stresses in tooth and the supporting 
tissue increased dramatically for the models with more than $50 \%$ bone reduction [49].

The peak VMS in bone component with normal bone height was $0.59 \mathrm{MPa}$ in buccal crest, $0.91 \mathrm{MPa}$ in lingual crest and $2.97 \mathrm{MPa}$ in apical region under axial loading, and increased 10 times and 7 times in buccal and lingual crest under non-axial loading respectively. The peak VMS under axial loading increased to $\times 5$ at buccal crest and to $\times 3.5$ and $\times 2.5$ at lingual crest in models 3 and 4 , and increased to $\times 5$ in buccal crest and to $\times 9$ in lingual crest in model 4 , under non-axial loadings, related to model 1 . The peak VMS in apical bone under axial loading increased to $\times 1.6$ and $\times 2$, and under non-axial loadings increased to $\times 1.5$ and $\times 5$ in models 3 and 4 . Compared to axial loading, the intensity rise under $\mathrm{BB}$ and WL loadings increased approximately to $\times 10-16$ at buccal and lingual bone crest in bone reduction models. In the alveolar bone under paraxial load, the highest stress of $49 \mathrm{MPa}$ was registered along the buccal crest of the tooth socket in the severe bone loss model, almost 16 times higher than the magnitude under axial load whose values equal to $3 \mathrm{MPa}$. However, the resulting bone stress at buccal and lingual bone crest was still lower than the reported yield bone strength of 120-167 MPa [43] that might cause detrimental effects on human tooth structure or periodontium. If the force of loading doubled, the bone might be damaged. This result clearly presents the mode of transmission eccentric occlusal forces onto surrounding alveolar bone structures, as well as their role in the possible bone resorption, commented in previous reports [24,50]. However, the stresses cannot be ignored, because repetitive fatigue loadings can potentially 'accumulate' the stress, causing cracking of tooth substances [25] or resorption or degeneration of the bone [51]. In spite of not having a maximum bearable stress levels for living tissues to continue normal biologic activities (maximum tolerable stress), stress increases might be so high depending on the direction and magnitude of occlusal loadings that they can be considered out of the range of tolerable stresses in our result.

This is the first report to demonstrate the stress profile and distribution generated by occlusal load as dissipated in root dentin and surrounding periodontal tissues, associated with reduced bone support in a 3D environment of lower premolar which is known to susceptible to occlusal trauma, to our best knowledges. FEA can predict the overall behavior of the tooth and bone supportive structures under different loading conditions, improving the understanding of biomechanical behavior that cannot be observed clinically. However, the results should be interpreted with caution due to its limitations as it is unable to precisely simulate the dynamic biomechanical phenomena that are associated with teeth and their support structures. Moreover, the employed loadings were static, while in a clinical condition, the movements are dynamic, cyclic and assume various positions. Other limitation of this FEA is that the materials from the different structures were assumed to have homogenous, isotropic, linear elastic properties, due to practicability of the analysis, although it was suggested that the finite element model of prismatic enamel should be constructed in consideration of the differences in enamel composition or prism orientation [52,53]. Besides, it was demonstrated that each component of dentin, bone and PDL also is not homogenous and has different property according to the anatomic location [53-56]. More precisely planned experiment is necessary for this issue, considering anisotropic characteristic of enamel on CEJ region and pulp property. Further studies might be useful in clarifying the influence of fatigue loading during repetitive cyclic occlusal loadings on risk of damage to the tooth and periodontal structures during function. Future study is also required to find such a maximum tolerable stress to enable these kinds of studies to determine the approximate or the exact limit of the occurrence of the unwanted events, while under load.

This study demonstrated the association between occlusal stress and NCCL, especially progression of root dentin lesion, and between eccentric loading and trauma of PDL in the presence if reduced bone height. In all models, the axial loading (V) resulted in lower peak VMS values and smaller extent of stress distribution in tooth and periodontal tissues regardless of supporting levels.

Under non-axial loading, peak VMS stress values increased prominently and the area of stress distribution became more extensive and shifted apically with the decreasing bone support. Loading direction made significant difference on the stress distribution pattern and intensity. 
From a mechanical perspective, for mobile tooth with weakened periodontium, occlusal diagnosis and subsequent re-adjustments of tooth contacts do provide patient comfort and relative stability of dentition and each tooth component.

\section{ACKNOWLEDGEMENTS}

The authors would like to thank to Dr. Hong-So Yang, professor of School of Dentistry, Chonnam National University, Gwangju, Korea, for his integral role in the fabrication of the finite element models. This study was financially supported by Chonnam National University (Grant Number: 2015-2651).

\section{CONFLICTS OF INTEREST}

The authors declare that they have no competing interests.

\section{ORCID}

\author{
Sun-Mi Yang \\ https://orcid.org/0000-0002-9802-0282 \\ Hyun-Ju Chung \\ https://orcid.org/0000-0001-8461-5093
}

\section{REFERENCES}

1. Khan F, Young WG, Shahabi S, Daley TJ. Dental cervical lesions associated with occlusal erosion and attrition. Aust Dent J 1999;44:176-186. doi: 10.1111/j.1834-7819.1999. tb00219.x.

2. Piotrowski BT, Gillette WB, Hancock EB. Examining the prevalence and characteristics of abfractionlike cervical lesions in a population of U.S. veterans. J Am Dent Assoc 2001;132:1694-1701; quiz 1726-7. doi: 10.14219/jada. archive.2001.0122.

3. Aw TC, Lepe X, Johnson GH, Mancl L. Characteristics of noncarious cervical lesions: a clinical investigation. J Am Dent Assoc 2002;133:725-733. doi: 10.14219/jada.archive.2002.0268.

4. Borcic J, Anic I, Urek MM, Ferreri S. The prevalence of non-carious cervical lesions in permanent dentition. J Oral Rehabil 2004;31:117-123. doi: 10.1046/j.0305182x.2003.01223.x.
5. Jakupovic S, Vukovic A, Korac S, Tahmiscija I, Bajsman A. The prevalence, distribution and expression of noncarious cervical lesions (NCCL) in permanent dentition. Mater Sociomed 2010;22:200-204.

6. Yoshizaki KT, Francisconi-Dos-Rios LF, Sobral MA, Aranha AC, Mendes FM, Scaramucci T. Clinical features and factors associated with non-carious cervical lesions and dentin hypersensitivity. J Oral Rehabil 2017;44:112-118. doi: 10.1111/joor.12469.

7. Que K, Guo B, Jia Z, Chen Z, Yang J, Gao P. A cross-sectional study: non-carious cervical lesions, cervical dentine hypersensitivity and related risk factors. J Oral Rehabil 2013;40:24-32. doi: 10.1111/j.1365-2842.2012.02342.x.

8. Madani AO, Ahmadian-Yazdi A. An investigation into the relationship between noncarious cervical lesions and premature contacts. Cranio 2005;23:10-15. doi: 10.1179/ crn.2005.003.

9. Paulander J, Axelsson P, Lindhe J, Wennström J. Intra-oral pattern of tooth and periodontal bone loss between the age of 50 and 60 years. A longitudinal prospective study. Acta Odontol Scand 2004;62:214-222.

10. Paulander J, Wennström JL, Axelsson P, Lindhe J. Some risk factors for periodontal bone loss in 50-year-old individuals. A 10-year cohort study. J Clin Periodontol 2004;31:489496. doi: 10.1111/j.1600-051X.2004.00514.X.

11. Borcic J, Anic I, Smojver I, Catic A, Miletic I, Ribaric SP. 3D finite element model and cervical lesion formation in normal occlusion and in malocclusion. J Oral Rehabil 2005;32:504-510.

12. Ichim I, Schmidlin PR, Kieser JA, Swain MV. Mechanical evaluation of cervical glass-ionomer restorations: 3D finite element study. J Dent 2007;35:28-35. doi: 10.1016/ j.jdent.2006.04.003.

13. Jakupović S, Anić I, Ajanović M, Korać S, Konjhodžić A, Džanković A, Vuković A. Biomechanics of cervical tooth region and noncarious cervical lesions of different morphology; three-dimensional finite element analysis. Eur J Dent 2016;10:413-418. doi: 10.4103/1305-7456.184166.

14. Reinhardt RA, Krejci RF, Pao YC, Stannard JG. Dentin stresses in post-reconstructed teeth with diminishing bone support. J Dent Res 1983;62:1002-1008.

15. Reinhardt RA, Pao YC, Krejci RF. Periodontal ligament stresses in the initiation of occlusal traumatism. J Periodontal Res 1984;19:238-246. doi: 10.1111/j.1600-0765.1984. tb00815.x.

16. Kuroe T, Caputo AA, Ohata N, Itoh H. Biomechanical effects of cervical lesions and restoration on periodontally compromised teeth. Quintessence Int 2001;32:111-118.

17. Kuroe T, Itoh H, Caputo AA, Nakahara H. Potential for load-induced cervical stress concentration as a function of periodontal support. J Esthet Dent 1999;11:215-222. doi: 10.1111/j.1708-8240.1999.tb00401.x.

18. Guimarães JC, Guimarães Soella G, Brandão Du- 
rand L, Horn F, Narciso Baratieri L, Monteiro S Jr, Belli R. Stress amplifications in dental non-carious cervical lesions. J Biomech 2014;47:410-416. doi: 10.1016/ j.jbiomech.2013.11.012.

19. Poiate IA, de Vasconcellos AB, de Santana RB, Poiate E. Three-dimensional stress distribution in the human periodontal ligament in masticatory, parafunctional, and trauma loads: finite element analysis. J Periodontol 2009;80:18591867. doi: 10.1902/jop.2009.090220.

20. Magne P. Efficient 3D finite element analysis of dental restorative procedures using micro-CT data. Dent Mater 2007;23:539-548. doi: 10.1016/j.dental.2006.03.013.

21. Zarone F, Sorrentino R, Apicella D, Valentino B, Ferrari M, Aversa R, Apicella A. Evaluation of the biomechanical behavior of maxillary central incisors restored by means of endocrowns compared to a natural tooth: a 3D static linear finite elements analysis. Dent Mater 2006;22:1035-1044. doi: 10.1016/j.dental.2005.11.034.

22. Farah JW, Craig RG, Meroueh KA. Finite element analysis of three- and four-unit bridges. J Oral Rehabil 1989;16:603611.

23. Geng JP, Tan KB, Liu GR. Application of finite element analysis in implant dentistry: a review of the literature. J Prosthet Dent 2001;85:585-598. doi: 10.1067/ mpr.2001.115251.

24. Jakupovic S, Cerjakovic E, Topcic A, Ajanovic M, Prcic AK, Vukovic A. Analysis of the abfraction lesions formation mechanism by the finite element method. Acta Inform Med 2014:22:241-245. doi: 10.5455/aim.2014.22.241-245.

25 . Rees JS. The effect of variation in occlusal loading on the development of abfraction lesions: a finite element study. J Oral Rehabil 2002;29:188-193. doi: 10.1046/j.13652842.2002.00836.x.

26. Lindhe J. Ericsson I.Trauma from occlusion: periodontal tissues. In: Lang NP, Lindhe J, editors. Clinical periodontology and implant dentistry. 6th ed. West Sussex: Wiley Blackwell; 2015. p. 313-324.

27. Picton DC. On the part played by the socket in tooth support. Arch Oral Biol 1965;10:945-955. doi: 10.1016/00039969(65)90088-9.

28. Serio FG, Hawley CE. Periodontal trauma and mobility. Diagnosis and treatment planning. Dent Clin North Am 1999;43:37-44.

29. Davies SJ, Gray RJ, Linden GJ, James JA. Occlusal considerations in periodontics. Br Dent J 2001;191:597-604. doi: 10.1038/sj.bdj.4801245.

30. Harrel SK, Nunn ME. The effect of occlusal discrepancies on periodontitis. II. Relationship of occlusal treatment to the progression of periodontal disease. J Periodontol 2001;72:495-505. doi: 10.1902/jop.2001.72.4.495.

31. Harrel SK, Nunn ME. The association of occlusal contacts with the presence of increased periodontal probing depth. J Clin Periodontol 2009;36:1035-1042. doi: 10.1111/
j.1600-051X.2009.01486.x.

32. Bernhardt O, Gesch D, Look JO, Hodges JS, Schwahn C, Mack F, Kocher T. The influence of dynamic occlusal interferences on probing depth and attachment level: results of the Study of Health in Pomerania (SHIP). J Periodontol 2006;77:506-516. doi: 10.1902/jop.2006.050167.

33. Branschofsky M, Beikler T, Schäfer R, Flemming TF, Lang H. Secondary trauma from occlusion and periodontitis. Quintessence Int 2011;42:515-522.

34. Duangthip D, Man A, Poon PH, Lo ECM, Chu CH. Occlusal stress is involved in the formation of non-carious cervical lesions. A systematic review of abfraction. Am J Dent 2017;30:212-220.

35. Spears IR, van Noort R, Crompton RH, Cardew GE, Howard IC. The effects of enamel anisotropy on the distribution of stress in a tooth. J Dent Res 1993;72:1526-1531.

36. Rees JS. The role of cuspal flexure in the development of abfraction lesions: a finite element study. Eur J Oral Sci 1998;106:1028-1032. doi: 10.1046/j.0909-8836.1998. eos106608.x.

37. Rees JS. An investigation into the importance of the periodontal ligament and alveolar bone as supporting structures in finite element studies. J Oral Rehabil 2001;28:425432. doi: 10.1046/j.1365-2842.2001.00686.x.

38. Palamara D, Palamara JE, Tyas MJ, Messer HH. Strain patterns in cervical enamel of teeth subjected to occlusal loading. Dent Mater 2000;16:412-419. doi: 10.1016/s01095641(00)00036-1.

39. Palamara JE, Palamara D, Messer HH, Tyas MJ. Tooth morphology and characteristics of non-carious cervical lesions. J Dent 2006;34:185-194. doi: 10.1016/j.jdent.2005.05.005.

40. Ferrario VF, Sforza C, Serrao G, Dellavia C, Tartaglia GM. Single tooth bite forces in healthy young adults. J Oral Rehabil 2004;31:18-22. doi: 10.1046/j.0305182x.2003.01179.x.

41. Gibbs CH, Mahan PE, Lundeen HC, Brehnan K, Walsh EK, Holbrook WB. Occlusal forces during chewing and swallowing as measured by sound transmission. J Prosthet Dent 1981;46:443-449. doi: 10.1016/0022-3913(81)90455-8.

42. Nakamura T, Imanishi A, Kashima H, Ohyama T, Ishigaki S. Stress analysis of metal-free polymer crowns using the three-dimensional finite element method. Int J Prosthodont 2001;14:401-405.

43. Tanaka M, Naito T, Yokota M, Kohno M. Finite element analysis of the possible mechanism of cervical lesion formation by occlusal force. J Oral Rehabil 2003;30:60-67. doi: 10.1046/j.1365-2842.2003.00959.x.

44. Giannini M, Soares CJ, de Carvalho RM. Ultimate tensile strength of tooth structures. Dent Mater 2004;20:322-339. doi: 10.1016/S0109-5641(03)00110-6.

45. Pikdöken L, Akca E, Gürbüzer B, Aydil B, Taşdelen B. Cervical wear and occlusal wear from a periodontal perspective. J Oral Rehabil 2011;38:95-100. doi: 10.1111/j.1365- 
2842.2010.02137.x.

46. Reddy K, Reddy S, Rao B, Kshitish D, Mannem S. Cervical stress due to normal occlusal loads is a cause for abfraction? - A finite element model study. J Orofac Sci 2012;4:120-123. doi: 10.4103/0975-8844.106204.

47. Ralph WJ. Tensile behaviour of the periodontal ligament. J Periodontal Res 1982;17:423-426. doi: 10.1111/j.16000765.1982.tb01172.x.

48. Wu B, Fu Y, Shi H, Yan B, Lu R, Ma S, Markert B. Tensile testing of the mechanical behavior of the human periodontal ligament. Biomed Eng Online 2018;17:172. doi: 10.1186/s12938-018-0607-0.

49. Vandana KL, Deepti M, Shaimaa M, Naveen K, Rajendra D. A finite element study to determine the occurrence of abfraction and displacement due to various occlusal forces and with different alveolar bone height. J Indian Soc Periodontol 2016;20:12-16. doi: 10.4103/0972-124X.168484.

50. Geramy A, Sharafoddin F. Abfraction: 3D analysis by means of the finite element method. Quintessence Int 2003;34:526-533.

51. Jepsen KJ, Davy DT. Comparison of damage accumulation measures in human cortical bone. J Biomech 1997;30:891894. doi: 10.1016/s0021-9290(97)00036-5.

52. Spears IR. A three-dimensional finite element model of prismatic enamel: a re-appraisal of the data on the Young's modulus of enamel. J Dent Res 1997;76:1690-1697.

53. Xu HH, Smith DT, Jahanmir S, Romberg E, Kelly JR, Thompson VP, Rekow ED. Indentation damage and mechanical properties of human enamel and dentin. J Dent Res 1998;77:472-480.

54. Konishi N, Watanabe LG, Hilton JF, Marshall GW, Marshall SJ, Staninec M. Dentin shear strength: effect of distance from the pulp. Dent Mater 2002;18:516-520. doi: 10.1016/ s0109-5641(01)00077-x.

55. Uhlir R, Mayo V, Lin PH, Chen S, Lee YT, Hershey G, Lin FC, Ko CC. Biomechanical characterization of the periodontal ligament: orthodontic tooth movement. Angle Orthod 2017;87:183-192. doi: 10.2319/092615-651.1.

56. Rho JY, Kuhn-Spearing L, Zioupos P. Mechanical properties and the hierarchical structure of bone. Med Eng Phys 1998;20:92-102. doi: 10.1016/s1350-4533(98)00007-1. 